Article

\title{
An Analytical Approach to Cutter Edge Temperature Prediction in Milling and Its Application to Trochoidal Milling
}

\author{
Qi Deng ${ }^{1}$, Rong Mo ${ }^{1}$, Zezhong C. Chen ${ }^{2}$ and Zhiyong Chang ${ }^{1, *}$ \\ 1 School of Mechanical Engineering, Northwestern Polytechnical University, 710072 Xi'an, China; \\ dengq@mail.nwpu.edu.cn (Q.D.); morong@nwpu.edu.cn (R.M.) \\ 2 Department of Mechanical and Industrial Engineering, Concordia University, 1455 De Maisonneuve Blvd. W. \\ Montreal, QC H3G 2W1, Canada; chencad@gmail.com \\ * Correspondence: changzy@nwpu.edu.cn; Tel.: +86-1367-917-8506
}

Received: 31 December 2019; Accepted: 16 January 2020; Published: 4 March 2020

check for updates

\begin{abstract}
Cutter edge temperature in milling is an important factor to cutter life. With high cutting speed and feedrate, the cutting efficiency is high; however, the cutter edge temperature is high, shortening the cutter life. Therefore, it is necessary to know the cutter edge temperature in milling. Unfortunately, the cutter edge temperature is difficult to measure and predict in milling. To address the technical challenge, an analytical approach was proposed to predict cutter edge temperature in milling. First, the heat flux into the cutter edge was calculated. Second, by using the Green function, the cutter edge temperature was figured out, and the results obtained from this approach agreed well with that of a recognized test. Then, based on the engagement between the cutter and workpiece in trochoidal milling, the cutter edge temperature was obtained in trochoidal milling. Finally, a temperature comparison was made between trochoidal and side milling based on this analytical approach, and the reasons that trochoidal machining could extend the cutter life were found. This approach is first proposed to calculate the cutter edge temperature in trochoidal milling and can be applied to machining parameters optimization in trochoidal milling and cutter design optimization.
\end{abstract}

Keywords: trochoidal machining; cutting temperature; cutting heat; milling; tool life

\section{Introduction}

Cutter edge temperature in milling is an important factor to cutter life. With high cutting speed and feedrate, the cutting efficiency is high; however, the cutter edge temperature is high, shortening the cutter life. Therefore, it is necessary to know the cutter edge temperature in milling. Unfortunately, the cutter edge temperature is hard to measure in milling, and the temperature is also difficult to predict. Recently, trochoidal milling has been widely adopted in the machining of hard-to-cut materials, such as mold steel, titanium and nickel-base alloy. Numerous industrial practices have demonstrated two advantages of trochoidal machining. (1) It could effectively reduce cutting temperature and extend cutter life up to 6 times, compared to the traditional side milling. (2) Its material removal rate (MRR) is high since aggressive cutting parameters, large axial cutting depth and fast feedrate could be employed due to small immersion angle between tool and workpiece. However, the application of trochoidal milling strategy in industry is still limited. To promote the efficient and widespread industrial applications of trochoidal machining strategy, the cutter edge temperature in trochoidal machining must be studied in depth, and, the reasons that trochoidal machining could greatly prolong the cutter life should be disclosed. However, there are few published works on this topic at present. To understand the pros and cons of current research, a comprehensive literature review is conducted here. 
Cutting forces affect cutting temperature significantly. Cutting forces and engagement in trochoidal machining have gained the attentions of many scholars. Otkur et al. [1] proposed a theoretical approach to calculating engagement angles and cutting forces during trochoidal machining. The cutting efficiency was greatly enhanced by employing a double trochoidal milling strategy. They concluded the cutting efficiency could be greatly improved by the strategy. Refs. [2,3] developed a model to optimize high speed trochoidal milling of pockets by taking the cutting forces, dynamic characteristics of machine tools, and shape of the workpiece into consideration. They argued trochoidal machining was superior to feedrate adjustment method in regulating cutting forces and extending cutter life at cavity machining. Deng et al. [4] presented an effective approach to optimize trochoidal toolpath based on cutting forces and machine tool kinematics. They pointed out that the engagement angle could be $\pi$ in traditional cavity milling, which will inevitably lead to large cutter load and high cutting temperature. $\mathrm{Li}$ et al. [5] constructed a novel trochoidal toolpath pattern for effective slotting; the cutting efficiency was enhanced, and immersion angles were limited by the given threshold. They confirmed that trochoidal milling strategy could reduce the cutter load and improve the heat dissipation, which is beneficial to extend the cutter life.

Plenty of researchers have found that trochoidal milling could improve the cutting efficiency compared with conventional milling. Ibaraki et al. [6] provided a practical way to generate trochoidal toolpath to cut the critical regions in cavity machining. They indicated that trochoidal machining was superior to contour-parallel machining in cutting the critical regions with careful design of toolpath, and the overall productivity could be improved without sacrificing the tool's life. Uhlmann et al. [7] carried out cutting experiments on Ti-Al6-V4 with two different strategies, conventional and trochoidal milling strategies. They found trochoidal milling strategy was superior to conventional milling strategy in cutting efficiency. Pleta et al. [8] made a comparison between trochoidal machining and traditional milling strategy in terms of cutting efficiency and tool wear. They discovered that trochoidal milling performed better in terms of productivity and cutter life by regulating the immersion angle and increasing the cutting parameters. Oh et al. [9] combined the laser-assisted machining with trochoidal machining to cut the difficult-to-cut materials. They discovered that the cutting load was greatly reduced, and the specific cutting energy could be saved.

Due to the effectiveness of trochoidal milling, a number of literatures focused on the optimization of trochoidal toolpath. Rauch et al. [10] provided a new technique to select the best trochoidal parameters, which could eliminate full immersion and keep the feed and acceleration smooth. They confirmed that the cutter life was extended by regulating radial depth of cut in trochoidal machining. Ferreira et al. [11] adopted medial axis transform to generate trochoidal toolpath in cavity milling. They found that the abrupt increasing of radial depth of cut was avoided, which made trochoidal milling advantageous in high speed machining. Salehi et al. [12] employed epicycloidal path to improve the trochoidal cutting efficiency. Simulations and experiments showed that the cutting time could be effectively reduced with little cutting load increase. Wang et al. [13] presented a novel trochoidal tool path generation technique, which could maintain radial depth of cut a constant, and avoid the un-necessary overlaps caused by conventional trochoidal tool path under constant trochoidal radius. They concluded that the radial depth of cut dominated the cutting forces and material removal rate. Li et al. [14] proposed a five-axis trochoidal flank milling strategy to machining complex 3D shaped cavities. Based on the given 3D cavity and the tool-workpiece engagement threshold, an optimized spatial cubic curve-based cyclic five-axis tool path could be generated. Finally, a practical application was given to show the correctness and effectiveness of the proposed model.

Recently, stability in trochoidal machining was also deeply analyzed for enhancing the cutting efficiency. Yan et al. [15] presented a method for obtaining the stability boundary of trochoidal machining considering trochoidal steps and spindle speeds. Later, they performed an experiment and found the proposed method could improve the machining efficiency. Niaki et al. [16] investigated the dynamic stability while trochoidal machining of IN718. The accurate chip profile during trochoidal 
milling was considered. They discovered that cutting parameters in trochoidal milling could be aggressively chosen without causing chatter, which was inevitable in traditional end milling.

The effects of cutting temperature on the cutter life have been investigated for years. Takeyama and Murata [17] studied the cutter life under common cutting conditions; the amount of flank wear was taken as the metric of tool life. The causes of tool wear were attributed to two categories, one was temperature related, and the other was temperature independent. Finally, they concluded that the tool life and cutting temperature were closely related, and an equation was given to estimate the cutter life. Ezugwu et al. [18] analyzed the main difficulties in machining titanium alloys and nickel-based superalloys. They pointed out that the cutter temperature could exceed $100{ }^{\circ} \mathrm{C}$ while machining the difficult to cut materials. This could soften the cutter edge and reduce the strength of the bonder, which will inevitably decrease the tool life. Finally, they concluded that cutter temperature was a critical factor that determined the tool life.

Since cutting temperature greatly affected the cutter life, plenty of researches have been focused on cutting temperature. Stephenson et al. [19-21] summarized the results of theoretical and experimental studies of tool temperature in interrupted cutting. They also investigated the temperature in semi-infinite rectangular corner heated by a time-varying heat flux. Toh [22] adopted the infrared temperature measurement technique to investigate cutting temperature of AISI H13 steel by up milling and down milling. They found that cutter temperature increased with bigger axial depth of cut and severer tool wear but was almost not affected by cutting directions. [23,24] introduced finite difference method to obtain the 3D temperature field during cutting operation, and simulation result was validated by measurement with an infrared camera. They indicated that the proposed method was time efficient and without losing accuracy when compared with finite element-based method. Palanisamy et al. [25] came up a method to predict the tool-chip temperatures for different machining conditions, based on cutting forces, Oxley's energy partition function and Rapier's equation. The predicted cutting temperature was demonstrated using a K-type thermocouple and an infrared pyrometer. Armendia et al. [26] developed a device, which could capture the temperature field variations in high speed intermittent cutting, based on infrared thermography. They pointed out the temperature along time in each cutter revolution could be approximately approached by exponential Heating/Cooling curves. Moreover, they indicated that thermal cycling could damage the cutter, and uncut time played an important part in cutting temperature. Jiang et al. [27] proposed an approach to estimating the temperature of cutter tooth and workpiece during intermittent cutting process, and the predicted results agreed well with the experiment measurement. Then, they confirmed that Salomon's hypothesis was true based on the proposed model and the experiment in cutting 1045 steel. $\mathrm{Wu}$ et al. [28] proposed a model to predicting the cutter temperature in end milling. The cutting cycle was divided into temperature increase and decrease phases, and they were studied separately. Finally, an experiment was provided to validate the effectiveness of the proposed method.

Previous researches on the cutting force, trochoidal toolpath, and stability of trochoidal machining are of great importance. They have demonstrated that trochoidal milling is able to extend cutter life, improve cutting efficiency, control cutting force, machine difficult-to-cut materials effectively. As has been discussed, cutting temperature plays an important role in tool life. Unfortunately, there were few researches focused on the cutting temperature during trochoidal milling, and this will hinder its further application.

In this work, a practical approach to predicting the cutting temperature in trochoidal machining was established. First, the heat flux that flows into the cutter during milling process was studied based on the numerical simulations performed on Deform 2D v11. After that, an analytical approach to predicting the cutting temperature in milling processed was proposed, and it was verified by compared with an elaborated research. Then, the engagement between the cutter and workpiece in trochoidal machining was analyzed, and the cutter edge temperature history in trochoidal machining was predicted for the first time. Finally, the cutter edge temperature patterns during trochoidal and 
side milling were extensively analyzed, and the reasons for the extended cutter life in trochoidal machining were illustrated in detail.

\section{Prediction of Cutter Edge Temperature in Milling}

In metal cutting, cutting power is mainly consumed by two areas, the primary shear zone and the secondary shear zone (see Figure 1). As indicated by Shaw [29], nearly all the cutting power was converted to heat, and Abukhshim et al. [30] pointed out that the heat generated in the second shear zone had a decisive effect on cutting temperature. Therefore, in this research, the cutting power in the second shear zone is extensively investigated. During machining, part of the cutting power is taken away by chips, while others flow into the cutter increasing its temperature. However, in trochoidal milling, the cutter edges cut inside and leave out the workpiece, so they undergo a complicated pattern of heating up and cooling down. To calculate cutter edge temperature in trochoidal milling, three steps are followed: (1) using a commercial finite element analysis software Deform 2D v11, the heat flux that flows into the cutter is computed with high fidelity; (2) a well-established method is adopted to describe the cutter's temperature variation, and the green function is used to solve it; and (3) a geometry model is established to represent the complex engagement between cutting edge and workpiece during trochoidal milling, and the engagement pattern is then combined into the calculation of cutting temperature.

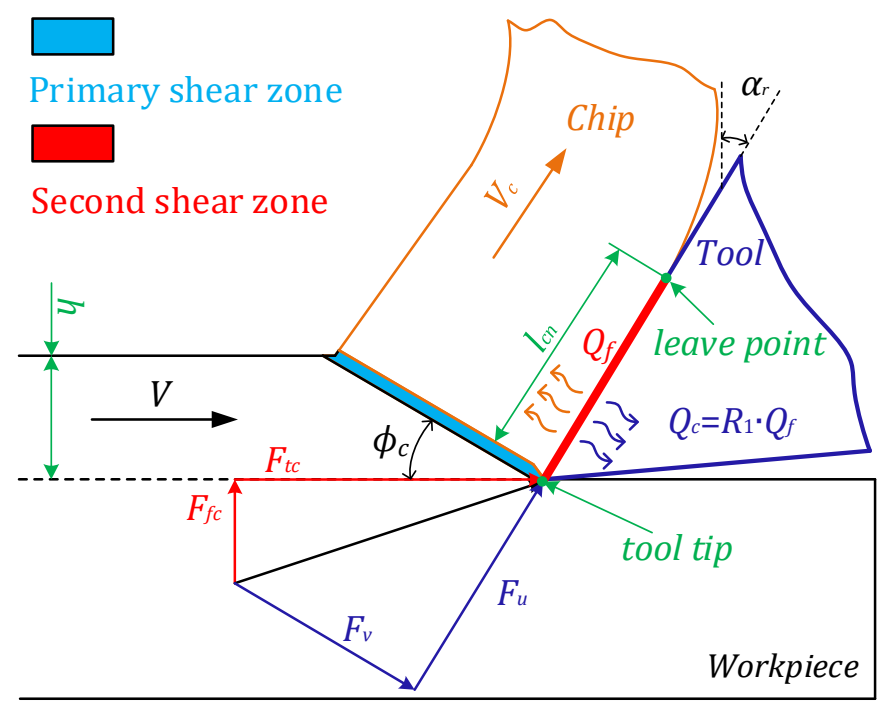

Figure 1. Cutting power consumption in metal cutting.

\subsection{Calculation of Heat Flux Into the Cutter}

As depicted in Figure 1, the cutting power consumed in the second shear zone is divided into two parts. The part that flows into the cutter increases the temperature of the cutting edge, and the corresponding heat flux $q_{c}$ is calculated as

$$
q_{c}=R_{1} \cdot Q_{f} / A_{s}
$$

where $R_{1}$ is the energy partition coefficient representing the fraction of heat that flows into the cutter, and its calibration is introduced in Section 3.2. $Q_{f}$ is friction power consumed in the rake face, and

$$
Q_{f}=F_{u} \cdot V_{c}
$$

where $F_{u}$ and $V_{c}$ are the friction force and chip velocity. For equilibrium, $F_{u}$ satisfies

$$
F_{u}=F_{t c} \cdot \sin \left(\alpha_{r}\right)+F_{f c} \cdot \cos \left(\alpha_{r}\right)
$$


where $F_{t c}$ is the main cutting force along cutter speed $V, F_{f c}$ is perpendicular to $F_{t c}$ (see Figure 1 ), and $\alpha_{r}$ is rake angle. In accordance with the principles of kinematics, the chip velocity is obtained by

$$
V_{c}=\frac{V \cdot \sin \left(\phi_{c}\right)}{\cos \left(\phi_{c}-\alpha_{r}\right)}
$$

where $\phi_{c}$ is shear angle. In Equation (1), $A_{s}$ is the area of chip-tool contact zone, and it is computed by

$$
A_{s}=l_{c n} \cdot a_{p}
$$

where $l_{c n}$ and $a_{p}$ are the contact length and axial depth of cut. Notice that by Equation (1), the heat flux $q_{c}$ is assumed to be distributed on the contact zone evenly.

In milling, the relationships of the cutting force, shear angle, and chip-tool contact length with respect to the un-deformed chip thickness $h$ are quite complicated. To represent the relationships, a commercial machining simulation software Deform 2D v11 is employed. The cutter is modelled as a rigid and heat transferable body, and the workpiece as an elastoplastic body. In one cut of an edge, the un-deformed chip thickness continually varies between 0 and feed per tooth $f_{z}$, so several ones of thickness $h_{i}$ in a cut are sampled

$$
h_{i}=i \cdot f_{z} / m, i=1,2, \ldots, m
$$

Each $h_{i}$ is fed into the machining simulation software, together with other parameters, the cutting speed, the rake angle, the friction coefficient between the cutter rake face and chip, etc., to evaluate the shear angle, the contact length, and the cutting forces. The input parameters and evaluation results are

\begin{tabular}{|c|c|c|}
\hline \multicolumn{3}{|r|}{ Input Parameters } \\
\hline Symbol & Unit & Remark \\
\hline$h_{i}$ & $\mathrm{~mm}$ & Sampled Un-deformed chip thickness, $i=1,2, \ldots, m$ \\
\hline$V$ & $\mathrm{~m} / \mathrm{s}$ & Cutting speed \\
\hline$\alpha_{r}$ & $\circ$ & Rake angle \\
\hline$\mu$ & & Friction coefficient between rake face and chip \\
\hline \multicolumn{3}{|r|}{ Evaluation Results } \\
\hline Symbol & Unit & Remark \\
\hline$F_{t c}^{i}$ & $\mathrm{~N}$ & $\begin{array}{l}\text { The cutting force in horizontal direction of cutting speed, under a specified } \\
\text { un-deformed thickness } h_{i}\end{array}$ \\
\hline$F_{f c}^{i}$ & $\mathrm{~N}$ & $\begin{array}{c}\text { The cutting force in vertical direction of cutting speed, under a specified } \\
\text { un-deformed thickness } h_{i}\end{array}$ \\
\hline$l_{c n}{ }^{i}$ & $\mathrm{~mm}$ & The chip tool contact under a specified un-deformed thickness $h_{i}$ \\
\hline$\phi_{c}{ }^{i}$ & $\circ$ & $\begin{array}{c}\text { The shear angle of the given tool-workpiece pair under the given cutter } \\
\text { parameters }\end{array}$ \\
\hline
\end{tabular}
listed in Table 1.

Table 1. The input parameters and evaluation results.

To represent the cutting forces as a function of un-deformed chip thickness, a well-established mechanistic cutting force model presented by Budak et al. [31] is introduced. The cutting forces are modelled as

$$
\left\{\begin{array}{l}
F_{t c}(h)=a_{p} \cdot\left(K_{t c} \cdot h+K_{t e}\right) \\
F_{f c}(h)=a_{p} \cdot\left(K_{f c} \cdot h+K_{f e}\right)
\end{array}\right.
$$

where $K_{t c}, K_{t e}, K_{f c}$ and $K_{f e}$ are the coefficients and they are determined by least square fitting to fit the model to the $m$ sampled thickness and the corresponding cutting forces. An example is plotted in Figure 2. 


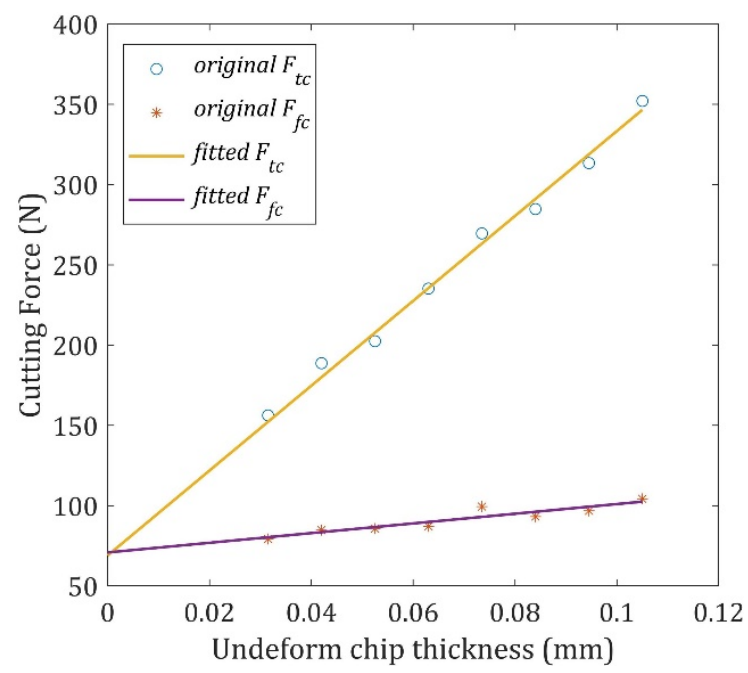

Figure 2. A number of sampled un-deformed thicknesses and corresponding cutting forces.

The shear angle and the contact length are manually evaluated, as depicted in Figure 3. For a specified $h_{i}$, three straight lines, $s_{1}{ }^{i}, s_{2}{ }^{i}$, and $s_{3}{ }^{i}$, are manually drawn according to the shear zone of the stress diagram and their angles with the horizontal line are measured. Then the shear angle is calculated as the average of the three angles,

$$
\phi_{\mathrm{c}}^{\mathrm{i}}=\left(\alpha_{1}^{i}+\alpha_{2}{ }^{i}+\alpha_{3}{ }^{i}\right) / 3
$$

The contact length $l_{c n}{ }^{i}$ corresponding to the specified $h_{i}$ is obtained on the stress diagram as well.

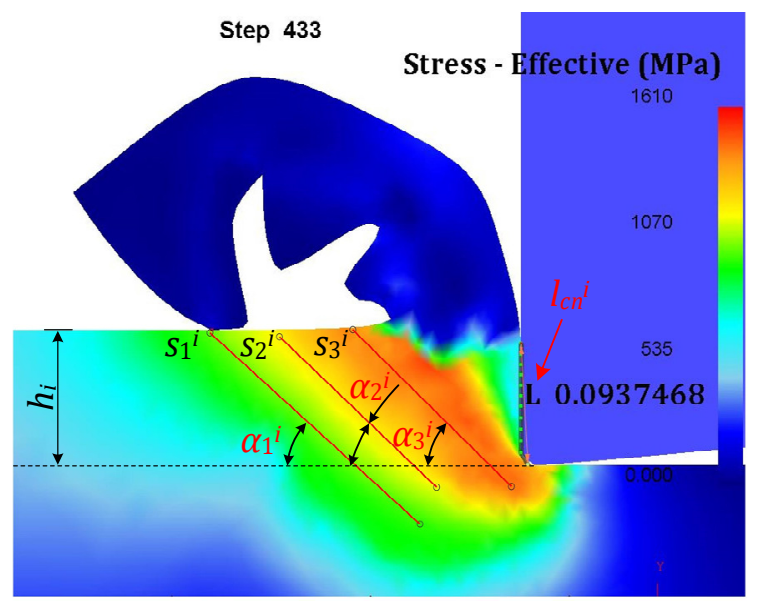

Figure 3. Evaluation of the shear angle and contact length based on the stress diagram.

Similarly, a linear function is adopted to describe the relationship between $l_{c n}$ and $h$

$$
l_{c n}(h)=k_{1} \cdot h+k_{0}
$$

where coefficients $k_{1}$ and $k_{0}$ are determined by least squaring fitting. An example is plotted in Figure 4 . For the shear angle, the simulation result reveals that it exhibits no significant change with different un-deformed chip thickness. Thus, shear angle is a thickness-independent constant. 


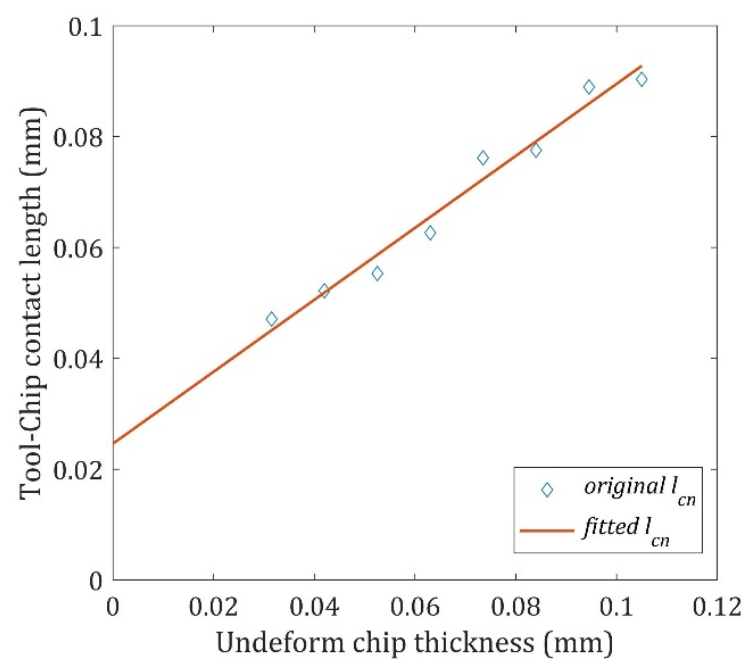

Figure 4. The relationship between the un-deformed chip thickness $h$ and contact length $l_{c n}$.

\subsection{Calculation of Cutter Edge Temperature in Milling}

In milling, the cutter is heated up mainly due to the heat that flows into the cutter through chip-tool contact zone. It has been verified that the heat convection effect is relatively insignificant if no coolant is used during machining, as demonstrated by Karaguzel et al. [32]. Hou et al. [33] pointed out that the heat radiation generated by cutting heat was generally weak; it had little impact on machining process. Therefore, heat convection and heat radiation effects are neglected in this study. Thus, it is reasonable to assume the boundary planes $x=0, y=0$, and $z=0$ depicted in Figure 5 are insulated. To calculate the cutter temperature, a local coordinate system is established (see Figure 5). For a location $A$ inside the cutter, if the thermal properties of the tool are homogeneous and are regarded as constant, its temperature $T$ satisfies

$$
\frac{\partial T}{\partial t}=K \cdot\left(\frac{\partial^{2} T}{\partial x^{2}}+\frac{\partial^{2} T}{\partial y^{2}}+\frac{\partial^{2} T}{\partial z^{2}}\right)
$$

where $T=T(x, y, z, t)$ is the temperature at position $(x, y, z)$ and time $t . K$ is the cutter thermal diffusivity. Equation (10) represents a 3-dimensional transient temperature problem, and its definite condition is

$$
\left\{\begin{array}{c}
-k \cdot \frac{\partial T}{\partial x}=q_{c}(t) \\
x=0 \\
0 \leq y \leq l_{c n} \\
0 \leq z \leq a_{p}
\end{array}\right.
$$

where $k$ is the cutter thermal conductivity, and $q_{c}(t)$ is the heat flux that flows into the cutter through chip-tool contact zone on the cutter rake. In this research, $q_{c}(t)$ is assumed to be evenly distributed on the contact zone.

To solve Equations (10) and (11), Ozisik's [34] theory is adopted. Then, the temperature $T$ is obtained by a triple integral

$$
T=\frac{K}{k} \cdot \int_{0}^{t} \int_{0}^{l_{c n}} \int_{0}^{a_{p}} \theta_{G}\left(x, y, z, y_{p}, z_{p}, D\right) \cdot q_{c}(\tau) \cdot d y_{p} \cdot d z_{p} \cdot d \tau
$$

where $\theta_{G}$ is green function and it represents the temperature rise at location $A$ of coordinate $(x, y, z)$ at time $t$ due to an instantaneous point heat source of unit strength at location $B\left(0, y_{p}, z_{p}\right)$ at time $t=\tau$. Green function is expressed as 


$$
\begin{aligned}
& \theta_{G}\left(x, y, z, y_{p}, z_{p}, D\right) \\
& =\frac{2}{(\sqrt{\pi} \cdot D)^{3}} \exp \left[\frac{-x^{2}}{D^{2}}\right] \cdot\left[\exp \left(\frac{-\left(y+y_{p}\right)^{2}}{D^{2}}\right)+\exp \left(\frac{-\left(y-y_{p}\right)^{2}}{D^{2}}\right)\right] \\
& \cdot\left[\exp \left(\frac{-\left(z+z_{p}\right)^{2}}{D^{2}}\right)+\exp \left(\frac{-\left(z-z_{p}\right)^{2}}{D^{2}}\right)\right]
\end{aligned}
$$

where $D=2 \sqrt{K \cdot(t-\tau)}$.

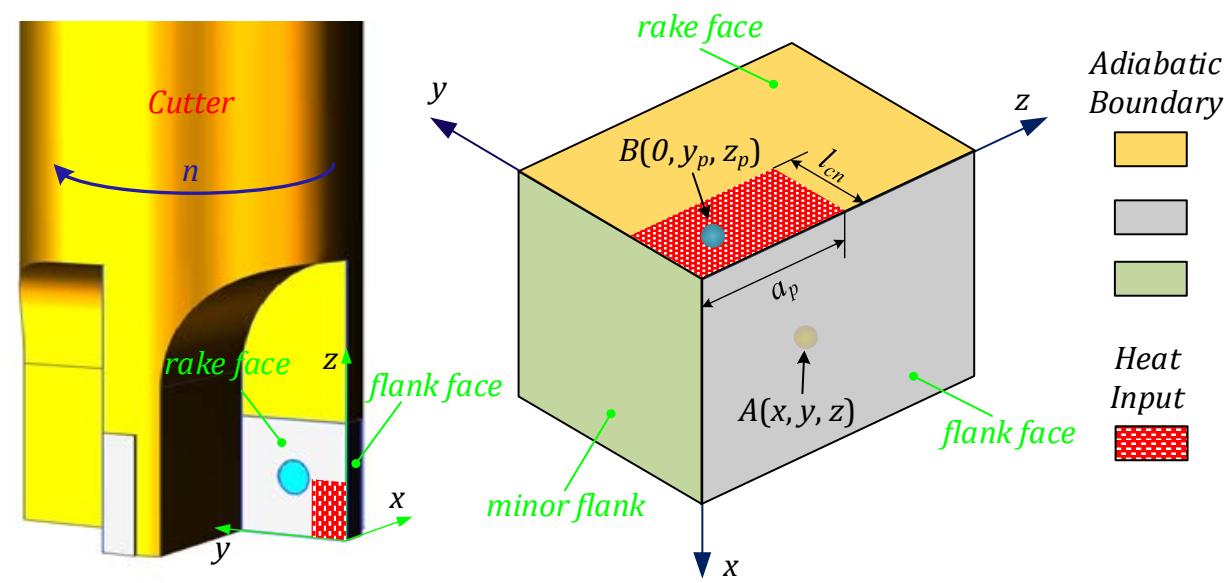

Figure 5. An illustration of the heat transfer problems in cutting process.

Because Equation (12) is complicated and cannot be evaluated analytically, the numerical methods are often employed, and these methods are usually time-consuming. To solve the temperature effectively, a simplification is conducted here. Since $q_{c}(t)$ is evenly distributed, which is independent of location, Equation (12) is simplified into an integral as

$$
T=\frac{K}{k} \int_{0}^{t} A(x, y, z, D) \cdot q_{c}(\tau) \cdot d \tau
$$

where

and

$$
\begin{aligned}
A(x, y, z, D) & =\int_{0}^{l_{c n}} \int_{0}^{a_{p}} \theta_{G}\left(x, y, z, 0, y_{p}, z_{p}, D\right) \cdot d y_{p} \cdot d z_{p} \\
& =\frac{1}{2 \sqrt{\pi} D} \exp \left(\frac{-x^{2}}{D^{2}}\right) \cdot\left[\operatorname{erf}\left(\frac{l_{c n}+y}{D}\right)+\operatorname{erf}\left(\frac{l_{c n}-y}{D}\right)\right] \\
& \cdot\left[\operatorname{erf}\left(\frac{a_{p}+z}{D}\right)+\operatorname{erf}\left(\frac{a_{p}-z}{D}\right)\right]
\end{aligned}
$$

$$
\operatorname{erf}(u)=\frac{2}{\sqrt{u}} \cdot \int_{0}^{u} e^{-\eta^{2}} \cdot d \eta
$$

By combining the engagement patterns between cutting edge and material, Equation (14) can be used to calculate cutter edge temperature in trochoidal milling.

\subsection{Engagement Patterns in Trochoidal Milling}

In trochoidal milling, the cutter is heated up and cooled down periodically. When the cutting edge cuts the material, the cutting edge is heated up because the heat generated flows into the cutter. While on the moments that the cutting edge leaves the material, the temperature starts to decrease. The engagement between cutting edges and material forms a complex pattern, and the pattern has a significant influence on cutter temperature.

For circular model, trochoidal toolpath is composed of lines and circles alternately. For illustration, a cycle of the line-segment $S E$ and the circle centered at $O_{1}$ is plotted in Figure 6, in which a workpiece with a slot is being machined along the trochoidal toolpath. The cutter radius is $R$, the segment length 
is $c$, and the circle radius is $r$. To figure out the engagement, a coordinate system $x O_{0} y$ is established here. The origin $O_{o}$ is located straight above the point $S$ with a distance $r$, and the $x$-axis is parallel to line $S E$.

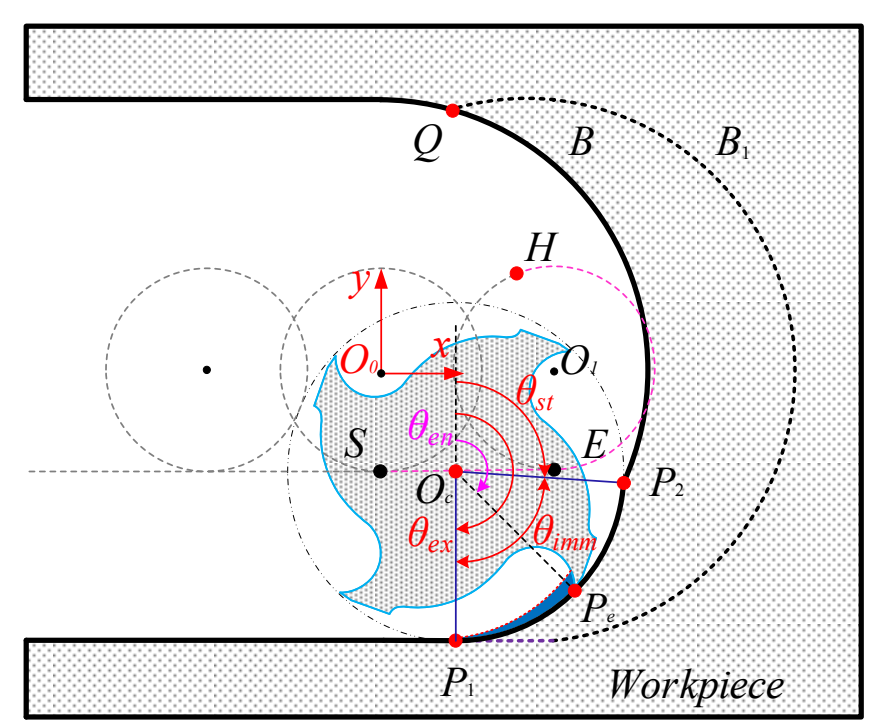

Figure 6. Geometrical relationship in trochoidal milling.

While the cutter feeds along $S E$ (see Figure 6), cutter center $O_{c}$ is formulated as

$$
\left[\begin{array}{l}
x_{c} \\
y_{c}
\end{array}\right]=\left[\begin{array}{c}
\frac{f}{60} \cdot t \\
-r
\end{array}\right], 0 \leq t \leq \frac{60 c}{f}
$$

where $f$ is feed speed ( $\mathrm{mm} / \mathrm{min}$ ), and $t$ is time parameter. Assume the cutter center is located on point $S$ at the moment $t=0$, and this moment is used as the reference to calculate the engagement. After $O_{c}$ reaches point $E$, the cutter starts to feed along the circle, and $O_{c}$ is formulated as

$$
\left[\begin{array}{l}
x_{c} \\
y_{c}
\end{array}\right]=\left[\begin{array}{c}
c+r \cdot \sin \left(\frac{f}{60 r} \cdot t-\frac{c}{r}\right) \\
-r \cdot \cos \left(\frac{f}{60 r} \cdot t-\frac{c}{r}\right)
\end{array}\right], \text { and } \frac{60 \cdot c}{f} \leq t \leq \frac{60 \cdot(c+2 \pi r)}{f}
$$

It is evident that when the cutter reaches point $H$ (see Figure 6), the whole cutter starts to leave the material, and no cutting edge engages with the material. The moment $t_{c}$ when the cutter reaches point $H$ is calculated as

$$
t_{c}=\left[\arcsin (c /(2(r+R)))+\pi+\frac{c}{r}\right] \cdot \frac{60 r}{f}
$$

While at a moment $t$ before $t_{c}$, the cutter is formulated as

$$
\left\{\begin{array}{l}
x=x_{c}+R \cdot \cos \beta \\
y=y_{c}+R \cdot \sin \beta
\end{array}, \text { and } \beta \in[0,2 \pi]\right.
$$

and the cutter intersects the workpiece with points $P_{2}$ and $P_{1}$ (see Figure 6). $P_{2}$ is the location where the cutting edges start to cut into the material, and $P_{1}$ is the location where the cutting edges leave the material. For the technical details of computing the location of $P_{2}$ and $P_{1}$, the readers can refer to our previous work Deng et al. [3]. The angle between $P_{2} O_{c}$ and the $y$-axis is called the entrance angle $\theta_{s t}$, and the angle between $P_{1} O_{c}$ and the $y$-axis is called the exit angle $\theta_{e x}$. The immersion angle is calculated as

$$
\theta_{\text {imm }}=\theta_{e x}-\theta_{s t}
$$


To determine whether a specified cutting edge $P_{e}$ is engaged into cut, its equation is formulated as

$$
\left\{\begin{array}{l}
x_{\mathrm{e}}=x_{c}+R \cdot \cos (n \cdot t \cdot \pi / 30) \\
y_{\mathrm{e}}=y_{c}+R \cdot \sin (n \cdot t \cdot \pi / 30)
\end{array}, 0 \leq t \leq \frac{60(c+2 \pi r)}{f}\right.
$$

where $n$ is spindle speed (rev/min). The angle $\theta_{e n}$ that lies between $P_{e} O_{c}$ and $y$ axis (see Figure 6) is the instantaneous engagement angle. The following two conditions are applied to determine the engagement between the cutting edge and the material.

Condition 1. $0 \leq t \leq \mathrm{t}_{\mathrm{c}}$.

If $\theta_{s t}<\theta_{e n}<\theta_{e x}$, the cutting edge cuts the material, and the instantaneous un-deformed chip thickness is

$$
h(t)=f_{z} \cdot \sin \left(\theta_{e n}\right)
$$

where $f_{z}$ is feed per tooth $(\mathrm{mm})$. Otherwise, the cutting edge is out of the material, and $h(t)=0$.

Condition 2. $\mathrm{t}_{\mathrm{c}} \leq t \leq \frac{60(c+2 \pi r)}{f}$.

The cutting edge leaves the material, and $h(t)=0$.

\section{Verification of the Proposed Method}

To verify the proposed method, a comparative analysis was made with Sato et al. [35], which gives an elaborate and comprehensive description of both simulation and experiment, making it a qualified reference.

\subsection{Specifications in Simulation and Experiment}

In Sato et al. [35], a single straight-tooth end-mill was used, for single tooth could reduce the influence of the cutter runout error. The cutter material is sintered carbide $\mathrm{K} 10$ without coating. The heat conductivity $k$ and thermal diffusivity $K$ of the material are $67 \mathrm{~W} /(\mathrm{m} \cdot \mathrm{K})$ and $2.2 \times 10^{-5} \mathrm{~m}^{2} / \mathrm{s}$, respectively. The details of the tool insert are depicted in Figure 7. A blind hole is drilled near the tool tip to install an optical fiber, which could capture the temperature signal in machining process. The radius of the hole is $0.5 \mathrm{~mm}$, and the position of the hole is also clearly shown in Figure 7 . The bottom of the blind hole lies underneath the rake face $[0.1,0.2,0.3,0.4,0.5] \mathrm{mm}$ for different measurement purposes. While the insert is mounted on the toolbar, the rake angle $\alpha_{r}=0^{\circ}$, clearance angle $\alpha_{c}=5^{\circ}$, and cutter radius $R=26 \mathrm{~mm}$. The insert edge radius $R_{0}=0.01 \mathrm{~mm}$. In Sato's simulation, the cutter is modeled as a rigid and heat transferable body. The material of the workpiece is Ti-6Al-4V, and its conductivity coefficient and specific heat are $7.955 \mathrm{~W} /(\mathrm{m} \cdot \mathrm{K})$ and $612 \mathrm{~J} /\left(\mathrm{Kg} \cdot{ }^{\circ} \mathrm{C}\right)$, respectively. The initial temperatures of the cutter and workpiece are all set to $25^{\circ} \mathrm{C}$ (the environment temperature). The friction coefficient of the given tool-workpiece pair is set to $\mu=0.6$. The machining parameters used in this verification are presented in Table 2 .

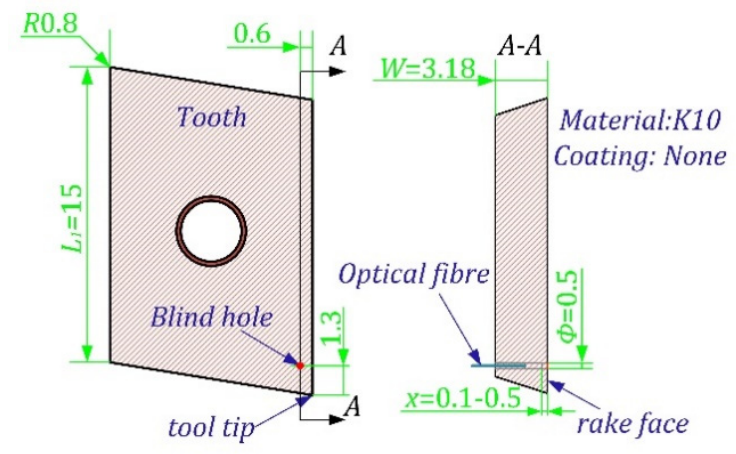

Figure 7. Details of the insert and the blind hole to install optical fiber (Sato et al. [35]). 
Table 2. Cutting parameters adopted in Sato et al. [35].

\begin{tabular}{cccccc}
\hline $\begin{array}{c}V \\
\mathbf{m} / \mathbf{m i n}\end{array}$ & $\begin{array}{c}f_{z} \\
\mathbf{m m} / \mathbf{z}\end{array}$ & $\begin{array}{c}\boldsymbol{a}_{e} \\
\mathbf{m m}\end{array}$ & $\begin{array}{c}\boldsymbol{a}_{p} \\
\mathbf{m m}\end{array}$ & $\begin{array}{c}n \\
\mathbf{r e v} / \mathbf{m i n}\end{array}$ & $\begin{array}{c}\boldsymbol{R} \\
\mathbf{m m}\end{array}$ \\
\hline 214 & 0.105 & 21 & 2 & 1310 & 26 \\
\hline
\end{tabular}

\subsection{Calibration of Energy Partition Coefficient}

Sato et al. [35] was conducted on side milling. For comparison, the complex pattern of trochoidal tool path described in Section 2.3 is not used in the verification. Instead, the simple pattern of side milling is given here and adopted. For a side milling with the cutting parameters listed in Table 2, the time of the cutter rotating one revolution is $0.0458 \mathrm{~s}$, for the first interval $t \in[0.0129,0.0229] \mathrm{s}$, the cutting edge cuts the material and the un-deformed chip thickness is $h(t)=0.105 \cdot \sin \left(7860.26^{\circ} \cdot t\right)$ in down milling. For the rest intervals $t \in[0,0.0129] \mathrm{s}$, and $t \in[0.0229,0.0458] \mathrm{s}$, the cutting edge leaves the material, $h(t)=0$, until the next revolution.

Using the proposed method mentioned in Sections 2.1 and 2.2, the temperature variation of a location inside the cutting edge is calculated. The coordinate of the location is $(0.1,0.6,1.3)$, which is the same location of the bottom of the blind hole in Sato's research. Moreover, the temperature is measured here. The calculated temperatures in a period of cutter's two revolutions are plotted in Figure 8 . In the calculation, three energy partition coefficients $R_{1}$ are employed, which are $40 \%, 50 \%$, and $60 \%$. The maximum and minimum temperatures calculated based on $R_{1}=[40 \%, 50 \%, 60 \%]$ are $\left(324.8{ }^{\circ} \mathrm{C}, 139.3{ }^{\circ} \mathrm{C}\right),\left(399.7^{\circ} \mathrm{C}, 169^{\circ} \mathrm{C}\right)$, and $\left(474.6{ }^{\circ} \mathrm{C}, 197.8^{\circ} \mathrm{C}\right)$, respectively.

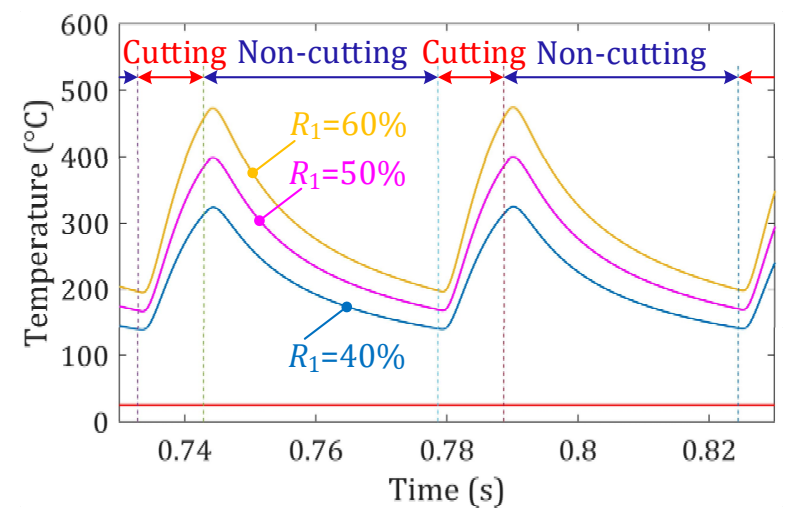

Figure 8. Temperature histories calculated by the proposed method at $(x, y, z)=(0.1,0.6,1.3)$.

The temperature history of simulations and experiments presented by Sato et al. [35] are shown in Figure 9a,b. Apparently, they matched well, and their maximum and minimum temperatures are $\left(407.9^{\circ} \mathrm{C}, 166.1^{\circ} \mathrm{C}\right)$. Evidently, when $R_{1}=40 \%$ or $R_{1}=60 \%$, the temperature differences between the calculated values and the reference are larger than $10 \%$. While $R_{1}=50 \%$, all the differences between the predicted and measured temperature values are less than $5 \%$. Thus, $R_{1}=50 \%$ is an appropriate energy partition efficient under the specification in Section 3.1. 

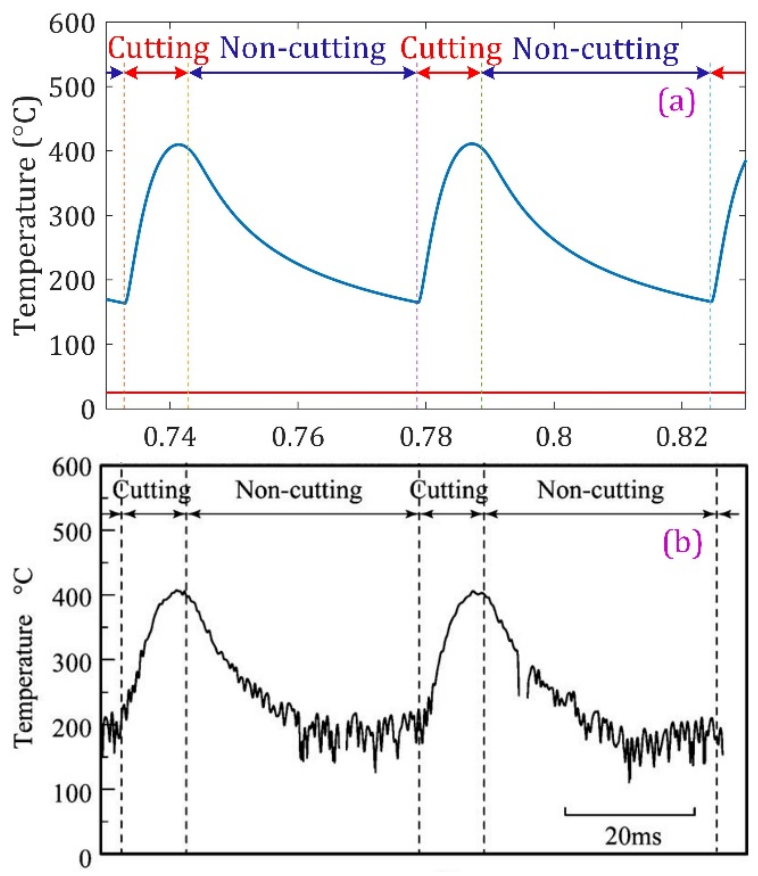

Figure 9. Temperature history at $(x, y, z)=(0.1,0.6,1.3)$ : (a) the simulation, and (b) the experiment, presented by Sato et al. [35].

\subsection{Comparison between Proposed Method and Sato's Results}

To demonstrate the validity of the proposed method, temperature histories of four more locations under the rake face at different depth, $(0.2,0.6,1.3),(0.3,0.6,1.3),(0.4,0.6,1.3)$ and $(0.5,0.6,1.3)$, are calculated and plotted in Figure 10a. The simulation results from Sato et al. [35] are shown in Figure 10b. Based on Figure 10a,b, the results obtained by the proposed method match well with the Sato's simulation results.
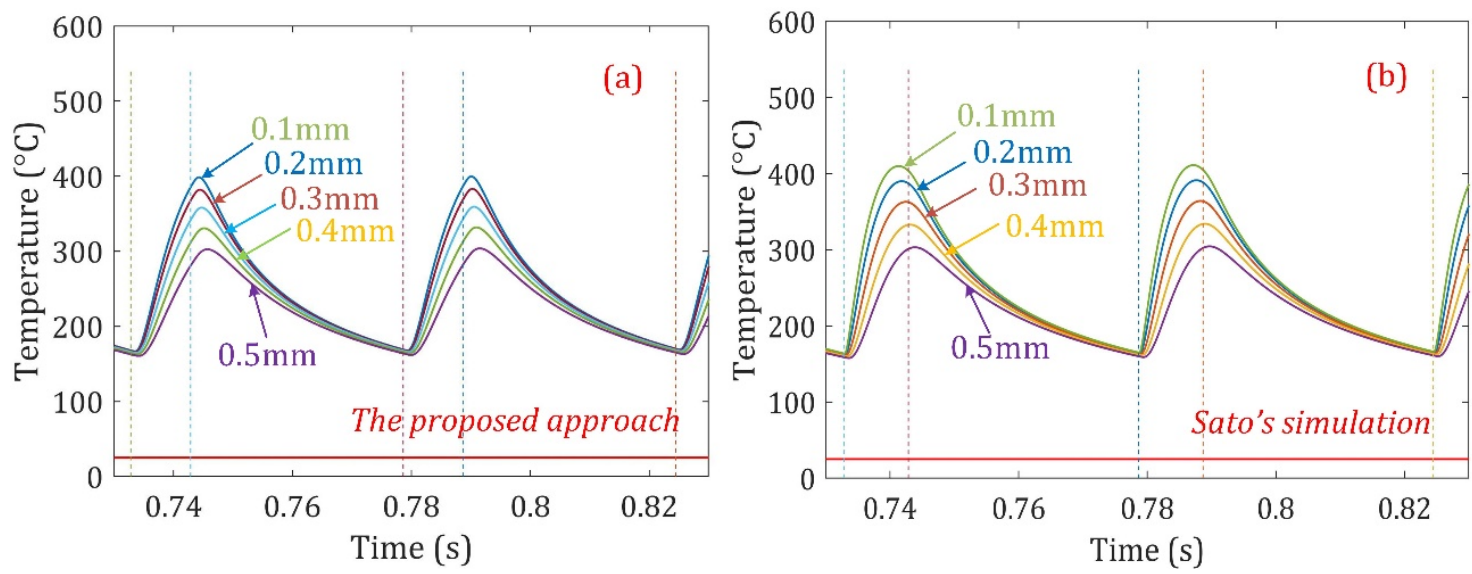

Figure 10. Temperature histories of different locations out of (a) the proposed method and (b) the simulation result obtained by Sato et al. [35].

The measured temperature histories of these locations were clearly shown in Sato et al. [35]. Here, a detailed comparison was made, the maximum predicted and measured temperatures during [0.73s, 0.83s] are presented in Table 3. The differences between them are also shown in Table 3. In general, the predicted results match the experiment well. As the depth from the rake face increases from 0.1 to $0.5 \mathrm{~mm}$, both the predicted and measured cutter edge temperature decreases. This is reasonable, because as depth from the rake face increases, the point of interest is getting away from the heat source. 
Thus, the temperature drops. According to Table 3, the measured temperature tends lower than the predicted temperature along the distance from the rake face increases. The reasons could be (1) the heat convection and radiation were neglected in this approach; (2) a small hole was drilled in the insert which will affect the temperature field of the cutter edge.

Table 3. Differences between the predicted and experimental results by Sato et al. [35].

\begin{tabular}{cccc}
\hline Depth & Predicted Max $\boldsymbol{T}$ & Measured Max $\boldsymbol{T}$ & Difference of Max $\boldsymbol{T}$ \\
\hline $0.1 \mathrm{~mm}$ & 399.7 & 407.9 & $-2.05 \%$ \\
$0.2 \mathrm{~mm}$ & 381 & 359.7 & $5.59 \%$ \\
$0.3 \mathrm{~mm}$ & 358 & 296.4 & $17.21 \%$ \\
$0.4 \mathrm{~mm}$ & 330.6 & 231.7 & $29.92 \%$ \\
$0.5 \mathrm{~mm}$ & 302.5 & 211.6 & $30.5 \%$ \\
\hline \multicolumn{4}{c}{}
\end{tabular}

Overall, the results obtained by the proposed method agree well with the Sato's simulation and experiment results. Thus, the proposed approach is valid and capable of predicting the temperature history in milling process.

\section{Results and Discussion}

In this section, the cutting temperature history during trochoidal milling is predicted for the first time, to the best of our knowledge, and its characteristics are analyzed. The relations between the immersion angle and the cutting temperature in trochoidal milling are illustrated in detail. Then a comparison between trochoidal and side milling is provided, trying to explain the reasons for the extended tool life in trochoidal milling.

\subsection{Cutter Edge Temperature in One Trochoidal Cycle}

Adopting the same tool-workpiece pair as in Section 3.1, a straight slot was machined by trochoidal milling strategy, as shown in Figure 6. Cutting parameters adopted are shown in Table 4. The period for the cutter feeding one trochoidal cycle is calculated to be $15.57 \mathrm{~s}$. By applied Equation (21), the immersion angles at a number of moments of the period are calculated and plotted in Figure 11. It is evident that the immersion angle gradually increases and reaches its maximum $\theta_{\max }=83.82^{\circ}$ at the moment $t=2.41 \mathrm{~s}$. This implies that cutting edges engage with the material for a longer period. Then the immersion angle starts to decrease until the cutter leaves the material at the moment $t_{c}=8.805 \mathrm{~s}$, which is calculated by Equation (19). After the moment $t_{c}$, no cutting edge cuts the material until next trochoidal cycle.

Table 4. Cutting parameters adopted during trochoidal machining.

\begin{tabular}{ccccccc}
\hline $\begin{array}{c}V \\
\mathbf{m} / \mathbf{m i n}\end{array}$ & $\begin{array}{c}f_{z} \\
\mathbf{m m} / \mathbf{z}\end{array}$ & $\begin{array}{c}\boldsymbol{a}_{p} \\
\mathbf{m m}\end{array}$ & $\begin{array}{c}\boldsymbol{n} \\
\mathbf{r e v} / \mathbf{m i n}\end{array}$ & $\begin{array}{c}\boldsymbol{R} \\
\mathbf{m m}\end{array}$ & $\begin{array}{c}c \\
\mathbf{m m}\end{array}$ & $\begin{array}{c}\boldsymbol{r} \\
\mathbf{m m}\end{array}$ \\
\hline 214 & 0.105 & 2 & 1310 & 26 & 4 & 5 \\
\hline
\end{tabular}




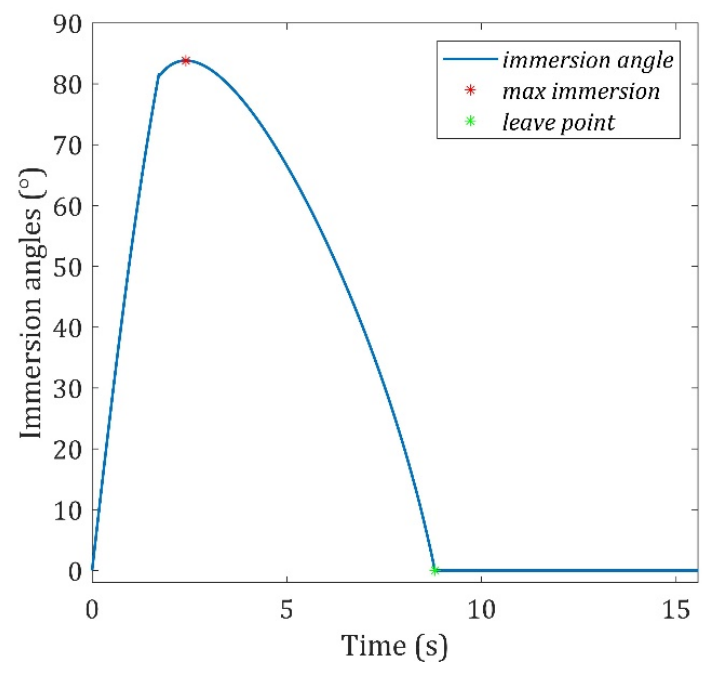

Figure 11. Immersion angles $\theta_{i m m}$ obtained of the trochoidal toolpath.

For the selected cutting edge, the heat flux $q_{c}$ during the machining of one trochoidal cycle is calculated by Equation (1) and plotted in Figure 12a. Three zoom-in diagrams at the intervals of $0.2308-0.3692 \mathrm{~s}, 2.3080-2.4460 \mathrm{~s}$, and 6.4620-6.600 s are presented in Figure 12b-d. In the interval of $0.2308-0.3692 \mathrm{~s}$ (Figure 12b), the cutter rotates three revolutions, and the cutting edge cuts the material three times. The cut-in and cut-out moments of each cut are marked with red and blue dot, respectively. From the cut-in moment to the cut-out moment of a cut, from 0.2769 to $0.2789 \mathrm{~s}$ for example, the heat that flows into the cutting edge is about $2.5 \times 10^{9} \mathrm{~W} / \mathrm{m}^{2}$, and the cutting edge is heated up for $0.0020 \mathrm{~s}$. While from the cut-out moment of the cut to the cut-in moment of the next cut, from 0.2789 to $0.3231 \mathrm{~s}$ for example, no heat flows into the cutting edge so it is cooling down for $0.0442 \mathrm{~s}$. The heat flux pattern and magnitude in Figure 12c are similar with those in Figure 12b. However, the heat-up time was extended to $0.0110 \mathrm{~s}$, and the cooling-down time was reduced to $0.0350 \mathrm{~s}$, in which situation a higher temperature on the cutting edge is expected.
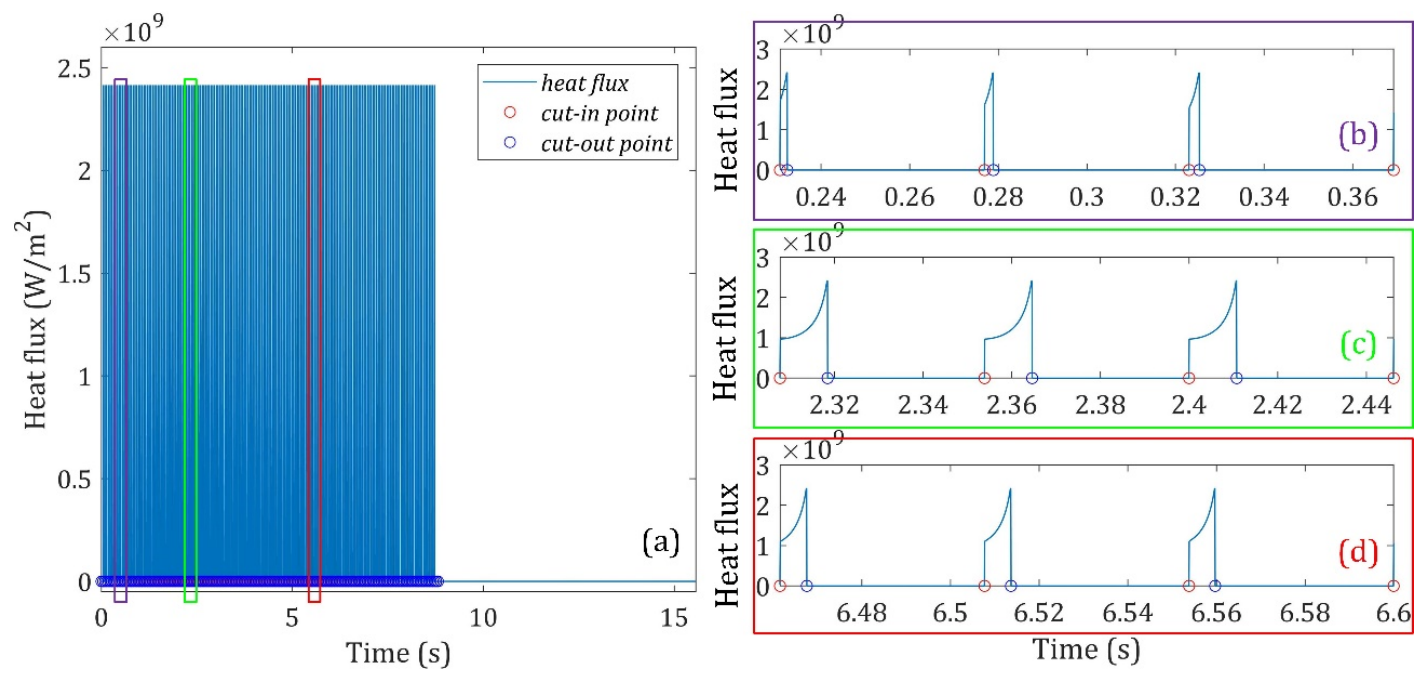

Figure 12. Heat flux $q_{c}$ flows into the cutter (a) in one trochoidal cycle, (b) at the interval of $0.2308-0.3692 \mathrm{~s}$, (c) at the interval of $2.3080-2.4460 \mathrm{~s}$ and (d) at the interval of $6.4620-6.600 \mathrm{~s}$.

To investigate the cutting-edge temperature, a location inside the cutter, $0.1 \mathrm{~mm}$ under its rake face, is selected to conduct the simulation. The location coordinate is $(0.1,0.6,1.3)$. By numerically solving Equation (14), the temperature of the location in a trochoidal cycle is calculated and plotted in Figure 13. A detailed zoom-in diagram is provided in the figure as well. In the interval of $6.45-6.60 \mathrm{~s}$ 
(see zoom-in Diagram in Figure 13), the cutter rotates three revolutions and the cutting edge cuts the material three times. Three temperature waves are observed in the diagram. The temperature rises rapidly at the beginning of the wave, after reaching its maximum $T_{\max }$, the temperature drops down sharply then drops a little slower. At the end of the wave, the temperature is down to its minimum $T_{\min }$, which is still higher than the environment temperature. After the moment $t_{c}=8.805 \mathrm{~s}$, the whole cutter leaves the material and the temperature keeps slowly dropping. At $t=15.57 \mathrm{~s}$, the temperature comes close to the environment temperature $\left(4.5^{\circ} \mathrm{C}\right.$ higher $)$.

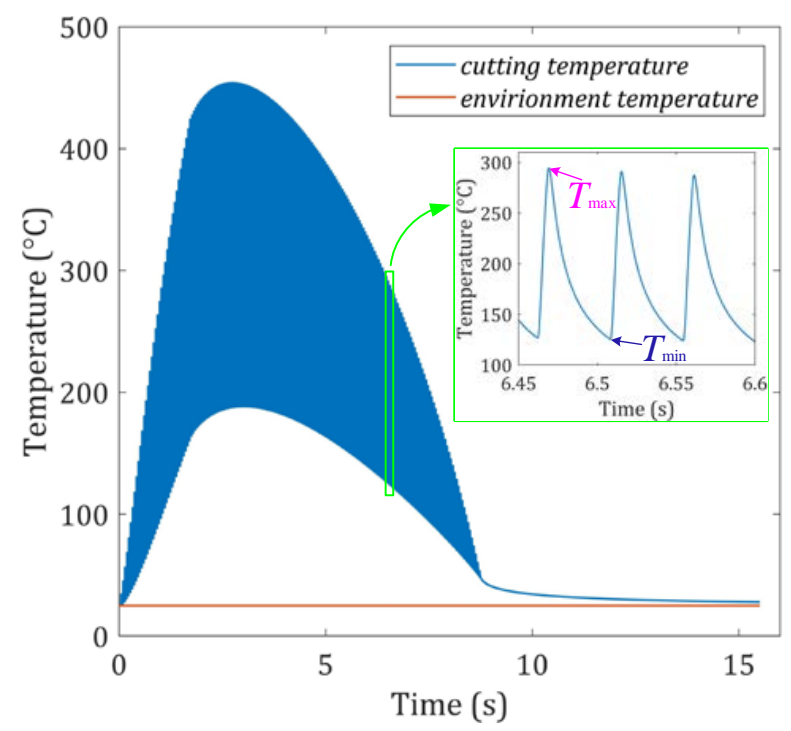

Figure 13. Cutting temperature during trochoidal machining.

Furthermore, the maximum and minimum temperatures of each wave, along with the immersion angle, are plotted together in Figure 14. A significant phenomenon is observed in the figure. The maximum temperature is well synchronized with the immersion angle and so is the minimum temperature. This is reasonable because the large immersion angle comes along with a longer cutting time, thus the cutting edge is heated up longer and consequently less time to release heat, and vice versa. Meanwhile, there is an apparent time lag between the maximum immersion angle and the max temperature $T_{\text {tromax }}$ out of the trochoidal cycle. The immersion angle reaches its maximum $\theta_{\max }=$ $83.82^{\circ}$ at the moment $t=2.4100 \mathrm{~s}$, and $0.3249 \mathrm{~s}$ later, $T_{\max }$ reaches its maximum $T_{\text {tromax }}=454{ }^{\circ} \mathrm{C}$ at the moment $t=2.7349 \mathrm{~s}$. This is partly because the location of interesting is $0.1 \mathrm{~mm}$ beneath the rake face, and heat transfer takes time.

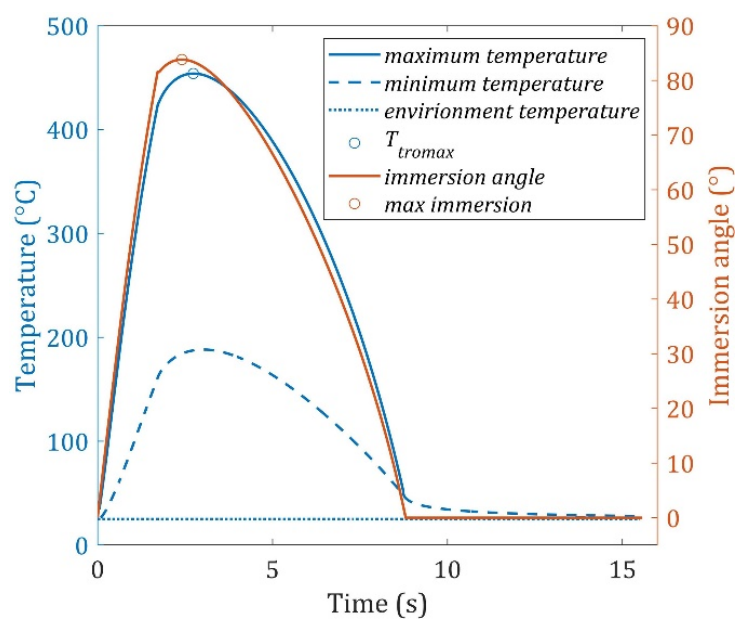

Figure 14. The cutting temperature and immersion angle during trochoidal machining. 


\subsection{Comparison between Temperatures in Trochoidal and Side Milling}

Trochoidal milling has been reported less tool wear than side milling, when removing the same volume of material, therefore the tool life is longer. Since cutting temperature has a significant influence on tool wear, a temperature comparison between trochoidal and side milling is conducted here.

The cutter, workpiece, cutting parameters, and trochoidal parameters described in Section 4.1 are adopted again. The maximum temperature $T_{\max }$ and the minimum temperature $T_{\min }$ out of six trochoidal cycle are calculated, and they are plotted in Figure 15. The maximum temperature $T_{\text {tromax }}$ of each trochoidal cycle is marked with black dots in the figure. The six $T_{\text {tromax }}$ are $454{ }^{\circ} \mathrm{C}, 456{ }^{\circ} \mathrm{C}, 456.7$ ${ }^{\circ} \mathrm{C}, 457^{\circ} \mathrm{C}, 457.3^{\circ} \mathrm{C}$, and $457.4{ }^{\circ} \mathrm{C}$, respectively. Apparently, $T_{\text {tromax }}$ is rising, but the variation is less than $0.75 \%$; more importantly, the rate of the change is decreasing and tends to zero. From the fifth to the sixth trochoidal cycle, $T_{\text {tromax }}$ only increases $0.1^{\circ} \mathrm{C}$. It is reasonable to predict that $T_{\text {tromax }}$ will be stable in the vicinity of $457.4^{\circ} \mathrm{C}$ even though more trochoidal cycles are calculated.

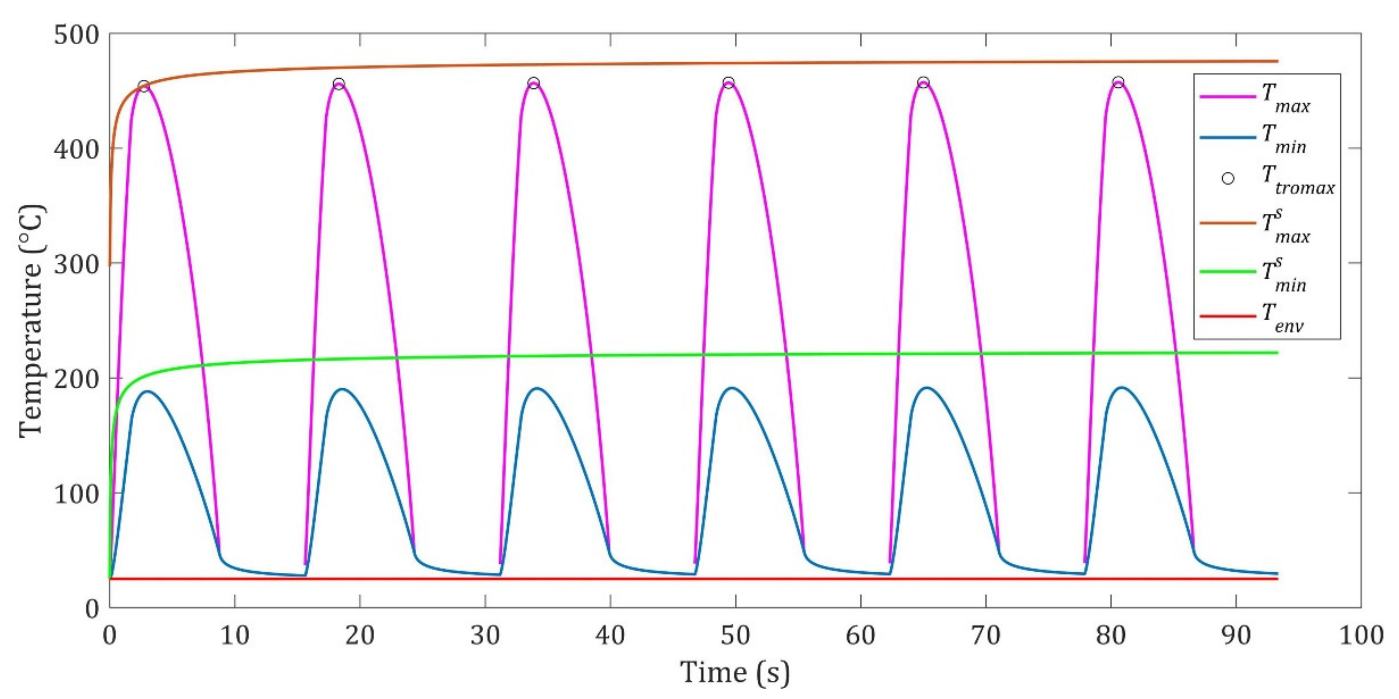

Figure 15. The cutting temperature of trochoidal and side milling.

For comparison, a side milling is simulated with our method. The cutter, workpiece and cutting parameters described in Section 4.1 are adopted. For comparison, radial depth of cut $a_{e}$ is set to 23.201 $\mathrm{mm}$ to ensure an immersion angle of $83.82^{\circ}$, same as the maximum immersion angle of the trochoidal cycle. The maximum temperature $T_{\text {max }}^{s}$ and minimum temperature $T_{\text {min }}^{s}$ of a cutting edge in the side milling are calculated and plotted in Figure 15. The maximum temperature rises dramatically for the first few seconds. After reaching $460.9{ }^{\circ} \mathrm{C}$, at the moment $t=4.959 \mathrm{~s}$, the temperature change slows down. At the moment $t=90 \mathrm{~s}$, the rate of change is close to zero (about $0.0026 \%$ ). This pattern is consistent with the reports by Kitagawa et al. [36] and Kountanya [37].

By comparison, $T_{\max }$ in trochoidal milling is found to be always lower than that $T^{s}{ }_{\max }$ in side milling and so is $T_{\text {min }}$. This indicates that the cutter cuts the material with trochoidal tool path, in general, in a lower cutting temperature than that in side milling. However, the maximum temperature $T_{\text {tromax }}$ of each trochoidal cycle is just a litter less than the $T^{s}{ }_{\text {max }}$ in side milling, for example a discrepancy of $17.95^{\circ} \mathrm{C}$ between trochoidal and side milling at the moment $t=80.57 \mathrm{~s}$ (see Figure 15). This may account for the extended tool life of trochoidal milling but should not be the only reason. Another probable cause of prolonged the tool life is further analyzed in the next section. 


\subsection{Thermal Shock in Trochoidal and Side Milling}

Plenty of researchers found that thermal shock played an important role in cutter life. To investigate the thermal shock in trochoidal milling, first, the thermal shock $T_{\text {shock }}$ is calculated based on the maximum and the minimum cutting temperature in one cutter revolution (see Figure 16)

$$
T_{\text {shock }}=T_{\max }-T_{\min }
$$

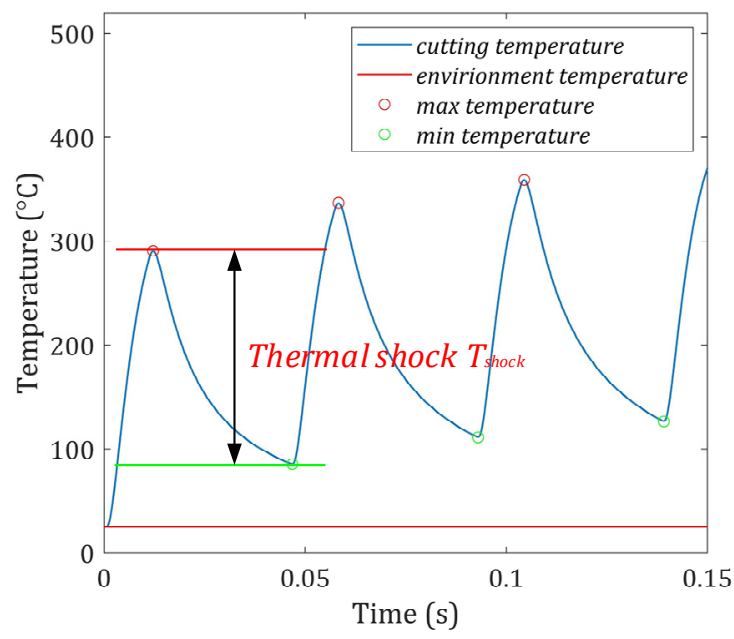

Figure 16. Definition of thermal chock.

Then, the cutting temperature between $31.55 \mathrm{~s}$ and $46.70 \mathrm{~s}$ in Figure 15 is designated to conduct the investigation, for it is stable and covered one trochoidal cycle. The thermal shock of trochoidal and side milling are calculated and plotted in Figure 17.

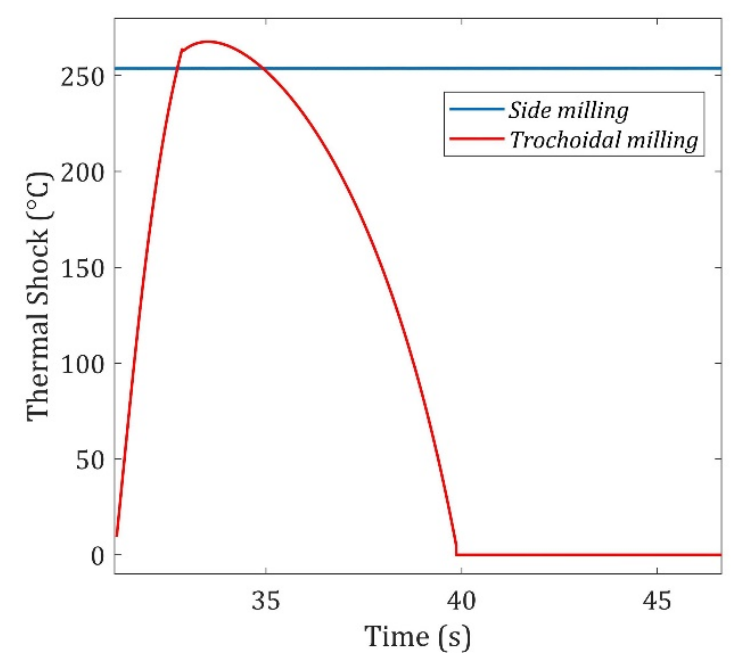

Figure 17. Thermal shock of trochoidal and side milling.

For side milling, its thermal shock keeps a constant of $253.7^{\circ} \mathrm{C}$. While in a cycle of trochoidal milling, the thermal shock gradually increases but lower than the side milling between $31.55 \mathrm{~s}$ and $32.76 \mathrm{~s}$. Then, the thermal shock of trochoidal milling is larger than that in side milling between 32.76 $\mathrm{s}$ and $34.93 \mathrm{~s}$, with a maximum of $14{ }^{\circ} \mathrm{C}$. Thereafter, the thermal shock of trochoidal milling is less than that in side milling and keeps decreasing, down to zero finally. By calculation, in the $86.1 \%$ of the whole trochoidal cycle time, the thermal shock of trochoidal milling is less than that of side milling. Therefore, we cautiously put forward an argument that the lesser thermal shock is a potential 
reason for trochoidal milling to prolong the cutter life. The argument is going to be examined with experiments in our further work.

\section{Conclusions}

This research has proposed a new and analytical method to investigate the cutter edge temperature in trochoidal milling. This work has presented an approach to calculating the heat flux into the cutter edge. It has proposed a model of the cutter edge temperature using the Green function, and this approach is verified by comparing its result with that of a recognized test. Based on the engagement analysis in trochoidal machining, the cutter edge temperature history is calculated for the first time as far as we know.

The proposed approach is effective in predicting the cutter edge temperature histories in both side and trochoidal milling process. During trochoidal machining, the maximum temperature is tightly related to the immersion angle, so is the minimum temperature. If the immersion angle increases, the cutter edge temperature will rise, and vice versa. Moreover, the temperature variation patterns in trochoidal machining become stable after a trochoidal cutting cycle. The cutting temperature in corresponding side milling also becomes stable after a trochoidal cutting period. These results will facilitate the choice of cutting parameters to control the cutting temperature in both side milling and trochoidal machining.

Two reasons have been found to decipher the cutter life extended phenomena in trochoidal machining. The first reason is that the temperature in trochoidal machining is lower than the temperature of corresponding side milling. The second reason is that the thermal shock in trochoidal machining is much smaller than the thermal shock in corresponding side milling. These two factors together make the trochoidal machining excel the traditional side milling in cutting difficult-to-cut materials, in which cutting temperature is always high, and the cutter life is generally short.

This research is original in terms of predicting cutter edge temperature in milling process. It can be used in machining parameter optimization and cutter design optimization.

Author Contributions: Q.D. methodology, validation, result analysis, and original draft preparation; R.M. supervision and project administration; Z.C.C. came up with ideas and edited the content; Z.C. reviewed and edited the manuscript. All authors have read and agreed to the published version of the manuscript.

Funding: This research was funded by the National Natural Science Foundations of China, grant number 51775445; the Aeronautical Science Foundation of China, grant number 2017ZE53053; and the major R\&D project of Shaanxi Province, grant number 2019GY-064 and 2016KTZDGY4-02.

Conflicts of Interest: The authors declare no conflict of interest.

\section{References}

1. Otkur, M.; Lazoglu, I. Trochoidal milling. Int. J. Mach. Tools Manuf. 2007, 47, 1324-1332. [CrossRef]

2. Wu, S.; Ma, W.; Li, B.; Wang, C. Trochoidal machining for the high-speed milling of pockets. J. Mater. Process. Technol. 2016, 233, 29-43.

3. Zhang, X.H.; Peng, F.Y.; Qiu, F.; Yan, R.; Li, B. Prediction of cutting force in trochoidal milling based on radial depth of cut. Adv. Mater. Res. 2014, 852, 457-462. [CrossRef]

4. Deng, Q.; Mo, R.; Chen, Z.C.; Chang, Z. A new approach to generating trochoidal tool paths for effective corner machining. Int. J. Adv. Manuf. Technol. 2018, 95, 3001-3012. [CrossRef]

5. Li, Z.; Xu, K.; Tang, K. A new trochoidal pattern for slotting operation. Int. J. Adv. Manuf. Technol. 2019, 102, 1153-1163. [CrossRef]

6. Ibaraki, S.; Yamaji, I.; Matsubara, A. On the removal of critical cutting regions by trochoidal grooving. Precis. Eng. 2010, 34, 467-473. [CrossRef]

7. Uhlmann, E.; Fürstmann, P.; Rosenau, B.; Gebhard, S.; Gerstenberger, R.; Müller, G. The potential of reducing the energy consumption for machining TiAl6V4 by using innovative metal cutting processes. In Proceedings of the 11th Global Conference on Sustainable Manufacturing, Berlin, Germany, 23-25 September 2013. 
8. Pleta, A.; Ulutan, D.; Mears, L. Investigation of trochoidal milling in nickel-based superalloy inconel 738 and comparison with end milling. In Proceedings of the ASME 2014 International Manufacturing Science and Engineering Conference collocated with the JSME 2014 International Conference on Materials and Processing and the 42nd North American Manufacturing Research Conference, Detroit, MN, USA, 9-13 June 2014.

9. Oh, N.S.; Woo, W.S.; Lee, C.M. A study on the machining characteristics and energy efficiency of Ti-6Al-4V in laser-assisted trochoidal milling. Int. J. Precis. Eng. Manuf. Green Technol. 2018, 5, 37-45. [CrossRef]

10. Rauch, M.; Duc, E.; Hascoet, J.Y. Improving trochoidal tool paths generation and implementation using process constraints modelling. Int. J. Mach. Tools Manuf. 2009, 49, 375-383. [CrossRef]

11. Ferreira, J.C.; Ochoa, D.M. A method for generating trochoidal tool paths for $2 \frac{1}{2} \mathrm{D}$ pocket milling process planning with multiple tools. Proc. Inst. Mech. Eng. B J. Eng. Manuf. 2013, 227, 1287-1298. [CrossRef]

12. Salehi, M.; Blum, M.; Fath, B.; Akyol, T.; Haas, R.; Ovtcharova, J. Epicycloidal versus trochoidal milling-Comparison of cutting force, tool tip vibration, and machining cycle time. Procedia CIRP 2016, 46, 230-233. [CrossRef]

13. Wang, Q.H.; Wang, S.; Jiang, F.; Li, J.R. Adaptive trochoidal toolpath for complex pockets machining. Int. J. Prod. Res. 2016, 54, 5976-5989. [CrossRef]

14. Li, Z.; Chen, L.; Xu, K.; Gao, Y.; Tang, K. Five-axis Trochoidal Flank Milling of Deep 3D Cavities. Comput. Aided Des. 2020, 119, 102775. [CrossRef]

15. Yan, R.; Li, H.; Peng, F.; Tang, X.; Xu, J.; Zeng, H. Stability prediction and step optimization of Trochoidal milling. J. Manuf. Sci. Eng. Trans. ASME 2017, 139, 091006. [CrossRef]

16. Niaki, F.A.; Pleta, A.; Mears, L.; Potthoff, N.; Bergmann, J.A.; Wiederkehr, P. Trochoidal milling: Investigation of dynamic stability and time domain simulation in an alternative path planning strategy. Int. J. Adv. Manuf. Technol. 2019, 102, 1405-1419. [CrossRef]

17. Takeyama, H.; Murata, R. Basic investigation of tool wear. J. Eng. Ind. 1963, 85, 33-37. [CrossRef]

18. Ezugwu, E.O.; Bonney, J.; Yamane, Y. An overview of the machinability of aeroengine alloys. J. Mater. Process. Technol. 2003, 134, 233-253. [CrossRef]

19. Stephenson, D.A. Assessment of steady-state metal cutting temperature models based on simultaneous infrared and thermocouple data. J. Eng. Ind. Trans. ASME 1991, 113, 121-128. [CrossRef]

20. Stephenson, D.A.; Ali, A. Tool temperatures in interrupted metal cutting. J. Eng. Ind. Trans. ASME 1992, $114,127-136$.

21. Stephenson, D.A.; Jen, T.C.; Lavine, A.S. Cutting tool temperatures in contour turning: Transient analysis and experimental verification. J. Manuf. Sci. Eng. Trans. ASME 1997, 119, 494-501. [CrossRef]

22. Toh, C.K. Comparison of chip surface temperature between up and down milling orientations in high speed rough milling of hardened steel. J. Mater. Process. Technol. 2005, 167, 110-118. [CrossRef]

23. Lazoglu, I.; Altintas, Y. Prediction of tool and chip temperature in continuous and interrupted machining. Int. J. Mach. Tools Manuf. 2002, 42, 1011-1022. [CrossRef]

24. Ulutan, D.; Lazoglu, I.; Dinc, C. Three-dimensional temperature predictions in machining processes using finite difference method. J. Mater. Process. Technol. 2009, 209, 1111-1121. [CrossRef]

25. Palanisamy, P.; Rajendran, I.; Shanmugasundaram, S.; Saravanan, R. Prediction of cutting force and temperature rise in the end-milling operation. Proc. Inst. Mech. Eng. B J. Eng. Manuf. 2006, 220, 1577-1587. [CrossRef]

26. Armendia, M.; Garay, A.; Villar, A.; Davies, M.A.; Arrazola, P.J. High bandwidth temperature measurement in interrupted cutting of difficult to machine materials. CIRP Ann. Manuf. Technol. 2010, 59, 97-100. [CrossRef]

27. Jiang, F.; Liu, Z.; Wan, Y.; Shi, Z. Analytical modeling and experimental investigation of tool and workpiece temperatures for interrupted cutting 1045 steel by inverse heat conduction method. J. Mater. Process. Technol. 2013, 213, 887-894. [CrossRef]

28. Wu, B.H.; Cui, D.; He, X.D.; Zhang, D.H.; Tang, K. Cutting tool temperature prediction method using analytical model for end milling. Chin. J. Aeronaut. 2016, 29, 1788-1794.

29. Shaw, M.C.; Cookson, J.O. Metal Cutting Principles, 2nd ed.; Oxford University Press: New York, NY, USA, 2005; pp. 206-207.

30. Abukhshim, N.A.; Mativenga, P.T.; Sheikh, M.A. Heat generation and temperature prediction in metal cutting: A review and implications for high speed machining. Int. J. Mach. Tools Manuf. 2006, 46, 782-800. [CrossRef] 
31. Budak, E.; Altintas, Y.; Armarego, E.J.A. Prediction of milling force coefficients from orthogonal cutting data. J. Manuf. Sci. Eng. Trans. ASME 1996, 118, 216-224. [CrossRef]

32. Karaguzel, U.; Bakkal, M.; Budak, E. Modeling and measurement of cutting temperatures in milling. Procedia CIRP 2016, 46, 173-176. [CrossRef]

33. Hou, Z.B.; He, S.J.; Li, S.X. Solid Heat Conduction; Shanghai Science and Technology Press: Shanghai, China, 1984.

34. Hahn, D.W.; Özisik, M.N. Heat Conduction, 3rd ed.; John Wiley Sons: Hoboken, NJ, USA, 2012.

35. Sato, M.; Tamura, N.; Tanaka, H. Temperature variation in the cutting tool in end milling. J. Manuf. Sci. Eng. Trans. ASME 2011, 133, 021005. [CrossRef]

36. Kitagawa, T.; Kubo, A.; Maekawa, K. Temperature and wear of cutting tools in high-speed machining of Inconel 718 and Ti-6Al-6V-2Sn. Wear 1997, 202, 142-148. [CrossRef]

37. Kountanya, R. Cutting tool temperatures in interrupted cutting-The effect of feed-direction modulation. J. Manuf. Process. 2008, 10, 47-55. [CrossRef]

(C) 2020 by the authors. Licensee MDPI, Basel, Switzerland. This article is an open access article distributed under the terms and conditions of the Creative Commons Attribution (CC BY) license (http://creativecommons.org/licenses/by/4.0/). 